\title{
Triple combination therapy and zeaxanthin for the treatment of neovascular age-related macular degeneration: an interventional comparative study and cost-effectiveness analysis
}

\author{
R. Joseph Olk ${ }^{1,2}$, Enrique Peralta ${ }^{1,2}$, Dennis L. Gierhart ${ }^{1,3}$, Gary C. Brown ${ }^{1,4^{*}}$ and Melissa M. Brown ${ }^{1,5}$
}

\begin{abstract}
Background: Reports of triple combination therapy for neovascular age-related macular degeneration (AMD) suggest a benefit, as do reports for zeaxanthin. An interventional comparative study was thus undertaken to evaluate the efficacy of triple combination therapy with and without zeaxanthin, as well as the economic viability of the therapies.

Methods: The cases of 543 consecutive eyes of 424 patients with subfoveal choroidal neovascularization (CNV) secondary to AMD were reviewed. All eyes were treated with triple combination therapy (triple therapy) consisting of: (1) reduced-fluence photodynamic therapy with verteporfin, (2) intravitreal bevacizumab and (3) intravitreal dexamethasone. Therapy was repeated as necessary. One cohort of patients was also given supplementation with $20 \mathrm{mg}$ of oral zeaxanthin (Zx) daily.

Results: The triple therapy group without $Z x$ received a mean of 2.8 treatment cycles and $87 \%$ of patients had stable or improved vision at 24 months. In the triple therapy group with Zx, the mean number of treatment cycles was 2.1, with $83 \%$ of patients having stable or improved vision at 24 months. At 24 months, CNV developed in $12.5 \%$ of fellow eyes treated with triple therapy alone; CNV developed in $6.25 \%$ of eyes treated with triple therapy with $Z x(p=0.03)$. An average cost-utility analysis revealed that triple therapy was cost-effective with a cost-utility ratio of $\$ 26,574$ / QALY, while triple therapy with Zx was more cost-effective with an average cost-utility ratio of \$19,962/QALY. The incremental cost-utility analysis assessing the addition of Zx to triple therapy disclosed Zx supplementation was very cost-effective at $\$ 5302 /$ QALY. When it was assumed that triple therapy with Zx reduced fellow eye CNV development by $30.3 \%$, the incremental cost-utility dropped to $(-\$ 6332 / \mathrm{QALY})$, indicating that adding Zx to triple therapy yielded greater patient value, and was also less expensive than using triple therapy alone.

Conclusions: Triple therapy is comparatively effective and cost-effective. Considerably less treatment is needed than reported in monotherapy studies. The addition of oral Zx appears to further reduce the treatment cycles required, and possibly reduce the risk of CNV development in the fellow eye.
\end{abstract}

Keywords: Zeaxanthin, Macular pigment, Combination therapy, Neovascular age-related macular neovascularization, Cost-effective

\footnotetext{
*Correspondence: gary0514@gmail.com; gbrown@valuebasedmedicine.

com

${ }^{1}$ The Center for Value-Based Medicine ${ }^{\circledR}$, Box 335, Flourtown, PA 19031,

USA

Full list of author information is available at the end of the article
} 


\section{Background}

Age-related macular degeneration (AMD) is the leading cause of vision loss in adults over age $50[1,2]$. The most severe vision loss occurs from choroidal neovascularization $(\mathrm{CNV})$ destroying macular structure and function. Vascular endothelial growth factor A (VEGF-A) has been identified as promoting CNV [3-5]. Studies have also noted the inverse association between the xanthophyll carotenoid zeaxanthin (Zx) and AMD pathogenesis [6, 7].

Current treatment options for neovascular AMD are multiple, but each has deficiencies. Photodynamic therapy with verteporfin (PDT) directly targets CNV. While it has been shown to be effective at selective destruction of vascular endothelial growth cells, the treatment incites an injured cell response that is counter-productive $[8,9]$.

Many studies have established anti-VEGF efficacy for CNV and AMD. The ANCHOR [10] and MARINA [11] studies demonstrated the benefit of monthly injections of ranibizumab, the CATT [12] study showed the equivalency of bevacizumab and ranibizumab, and the PIER and PRONTO Studies [13] showed decreased frequency of treatment can still be effective. Overall cost and the burden of frequent injections, however, diminish satisfaction with this therapy.

The presence of an inflammatory component to AMD is now well established [14]. Thus, there is also a rationale for the use of corticosteroids for treating neovascular AMD $[15,16]$.

A limited number of studies have begun to evaluate the possible synergy created through a combination of the three treatment modalities: PDT, anti-VEGF therapy and corticosteroids $[15,16]$. These studies seem to balance efficacy and treatment burden.

Major epidemiology studies [17-20] have shown that both higher dietary and serum levels of lutein and Zx are associated with significantly lower odds ratios of AMD. The AREDS Study Group [19] found higher dietary intakes of lutein and $\mathrm{Zx}$ reduced progression of both wet and dry AMD. The findings were so significant that the AREDS II was undertaken to study these specific effects.

In this study, we sought to further explore triple combination therapy (triple therapy) potential for CNV, with the thought of reducing treatment burden at a reduced cost compared to monotherapy treatments. In addition, we investigated the added effect of oral Zx. This paper is NOT a randomized clinical trial, but rather an interventional comparative study of two cohorts of patients treated for neovacular AMD. One cohort was treated with triple therapy alone, the other with triple therapy plus oral Zx. Recognizing the limitations of an interventional comparative study, the investigation was also undertaken to assess whether a prospective, randomized, controlled trial should be considered.

\section{Patients and methods}

This comparative interventional study enrolled 424 participants with 543 eyes with neovascular AMD. The consecutive triple therapy without $\mathrm{Zx}$ patients were treated initially. When the lead author discovered the theoretical benefits of oral $\mathrm{Zx}$, this was added to triple therapy. Thus, the triple therapy with Zx cohort participants were all enrolled after all of the cohort without Zx participants were already enrolled and had begun treatment.

Inclusion criteria Participants with classic, minimally classic, and/or occult subfoveal CNV were enrolled. Only eyes with macular blood, subretinal fluid, and/or retinal edema with characteristic CNV findings confirmed by fluorescein angiography, optical coherence tomography (OCT) or indocyanine green angiography were included.

Exclusion criteria Eyes with greater than 12 optic disc areas of CNV were excluded. Eyes with less than 20/400 vision were also excluded. The presence of blood was not an exclusion feature unless it covered greater than 12 disc areas.

Demographic features Two hundred seventy-nine participants were female and 145 were male. The mean age was 80 years, with a range from 50 to 99 years. All patients were taking a multi-vitamin (usually Centrum Silver; Pfizer) and an AREDS I antioxidant regimen (usually PreserVision; Bausch \& Lomb) during the trial.

Triple therapy patients without zeaxanthin In this group there were 290 eyes of 210 patients; 182 were female and 58 male, with an age range of 50-99 and a mean age of 82 . Eighty patients presented with bilateral $\mathrm{CNV}$ and 130 patients had unilateral CNV. Two hundred sixty-one eyes $(90 \%)$ were followed for 12 months and 206 eyes $(71 \%)$ for 24 months. Baseline visions ranged from $20 / 30$ to $20 / 400$, with a mean LogMAR visual acuity of 1.12 [20/250]. Patients received an intravitreal injection of $1.25 \mathrm{mg}$ of bevacizumab at the initial visit, 1000 micrograms of intravitreal dexamethasone within 1 week, and reduced-fluence (PDT), usually within 2 weeks from baseline. PDT therapy utilized $25 \mathrm{~mJ}$ for $83 \mathrm{~s}$. This protocol constituted one cycle of treatment. Reduced-fluence PDT was selected because full-fluence appears to cause more long-term retinal thinning [21]. Other authors have used half-fluence PDT with triple therapy with success [22].

After the initial treatment cycle, patients were re-examined within 4-6 weeks. Once deemed stable, follow-up was undertaken every 6-8 weeks in year one and every 8-12 weeks in year two. Retreatment was based on the presence of any of the following: subretinal fluid/blood on clinical exam, intraretinal or subretinal fluid on optical coherence tomography (OCT), decrease in vision, late leakage on fluorescein angiography, or an occult plaque 
on indocyanine green angiography. When retreatment was necessary, triple therapy was given.

Triple therapy patients with $Z x$ The second consecutive series comprised 253 eyes of 214 patients, 127 female and 87 male. Their ages ranged from 53 to 97 , with a mean of 80 years. One hundred twenty-one eyes $(94.1 \%)$ were followed for 12 months and 93 eyes (72.4\%) were followed for 24 months. Visual acuity ranged from 20/30 to 20/400 at baseline, with a mean initial LogMAR visual acuity of $1.00(20 / 200)$. This second cohort was treated with triple therapy identical to the first. In addition, participants were given oral zeaxanthin, $20 \mathrm{mg}$, daily (Eye Promise Zeaxanthin, ZeaVision), for 2 years. Retreatment criteria were the same.

\section{The economic model}

Incremental and average cost-utility analyses were performed using a Value-Based Medicine ${ }^{\circledR}$ (standardized) cost-utility model [23, 24]. Patient time tradeoff utilities, a third party insurer cost-perspective and national, average, Medicare Fee Schedule costs (Table 1) were utilized. The base case employed an incremental cost-utility analysis comparing triple combination therapy with $\mathrm{Zx}$ to triple combination therapy without Zx for neovascular AMD. Average cost-utility analyses compared triple therapy with $\mathrm{Zx}$ to no treatment and triple therapy to no treatment.

\section{Model time frame}

A nine-year time frame was used, the mean life expectancy for the average 81-year-old in the combined cohorts. A LOCF (last observation carried forward) methodology was employed from 25 months to 9 years. The base case assumed oral Zx was continued for 9 years.
A theoretical control cohort for both cohorts was created using data from Shah and DelPriore [25]. They analyzed control cohort visions from six randomized, neovascular AMD clinical trials with a Lineweaver-Burke model, demonstrating the mean vision associated with untreated neovascular AMD correlated with the time since onset of CNV. By the ninth year, the mean vision associated with untreated neovascular AMD deteriorated to $20 / 640^{+1}$ (Table 2).

\section{First-eye, second-eye models}

The concept of first-eye, second-eye and combined-eye models was developed at the Center for Value-Based Medicine ${ }^{\circledR}$ based upon primary patient data [23, 24, 26, 27]. They are based upon observations that vision-related quality-of-life most closely correlates with vision in the better-seeing eye. The first-eye model indicates the first eye is under treatment and the second eye is unaffected by the disease, neovascular AMD herein. The second-eye model indicates the first eye already has vision loss from the untreated disease. As clinicians know, losing vision in a second eye in addition to the first is devastating if untreated. Thus, the second-eye model yields the greatest patient value gain with therapy. The combined-eye model is simply the weighted average of the first-eye and second-eye models. The combined-eye model was used for the base case cost-utility analysis herein.

\section{Patient preference-based comparative effectiveness}

Study data were converted to a patient preference-based format to quantify quality-of-life using time tradeoff utilities obtained from over 1100 interviews with ophthalmic patients $[23,24]$. Utilities are often referred to as patient preferences since patients can prefer to trade something

Table 1 Average national medicare costs in 2015 US nominal dollars

\begin{tabular}{|c|c|c|}
\hline Intervention & CPT code & Cost per treatment \\
\hline Visudyne dye for PDT therapy & J3396 & $\$ 1613$ \\
\hline Intravitreal bevacizumab, 1.25 mg & J9035 & $\$ 68$ \\
\hline Intravitreal dexamethasone, 1 mg & $J 1100$ & $\$ 10$ \\
\hline Photodynamic therapy physician fee & 67,221 & $\$ 298$ \\
\hline Intravitreal injection of medication & 67,028 & $\$ 106$ \\
\hline Fundus photography & 92,250 & $\$ 79$ \\
\hline Intravenous fluorescein angiography & 92,235 & $\$ 111$ \\
\hline Indocyanine green angiography & 92,240 & $\$ 256$ \\
\hline Optical coherence tomography & 92,134 & $\$ 46$ \\
\hline Ophthalmological services, medical examination and evaluation & 92,004 & $\$ 151$ \\
\hline Ophthalmological services, medical examination and evaluation & 92,012 & $\$ 87$ \\
\hline Ophthalmological services, medical examination and treatment & 92,014 & $\$ 126$ \\
\hline Eye Promise Zeaxanthin ${ }^{a}$, Zea Vision, 20 mg per day, 1-year cost & NA & $\$ 360$ \\
\hline
\end{tabular}

CPT current procedural terminology, the interventional classification utilized by Medicare, NA not applicable

a Not included within the Medicare CPT codes 
Table 2 Mean visual acuity in the triple combination therapy with zeaxanthin, triple combination therapy without zeaxanthin and control cohorts

\begin{tabular}{llll}
\hline Year & $\begin{array}{l}\text { Triple combination } \\
\text { therapy with } \\
\text { zeaxanthin cohort }\end{array}$ & $\begin{array}{l}\text { Triple combina- } \\
\text { tion therapy } \\
\text { cohort }\end{array}$ & $\begin{array}{l}\text { External control } \\
\text { cohort (Shah } \\
\text { and DelPriore) }\end{array}$ \\
\hline 1 & $20 / 200$ & $20 / 250$ & $20 / 200$ \\
2 & $20 / 160+2$ & $20 / 200+1$ & $20 / 250-2$ \\
3 & $20 / 160+2$ & $20 / 200+1$ & $20 / 320-2$ \\
4 & $20 / 160+2$ & $20 / 200+1$ & $20 / 400-1$ \\
5 & $20 / 160+2$ & $20 / 200+1$ & $20 / 500+1$ \\
6 & $20 / 160+2$ & $20 / 200+1$ & $20 / 500-1$ \\
7 & $20 / 160+2$ & $20 / 200+1$ & $20 / 500-2$ \\
8 & $20 / 160+2$ & $20 / 200+1$ & $20 / 500-2$ \\
9 & $20 / 160+2$ & $20 / 200+1$ & $20 / 640+1$ \\
\hline
\end{tabular}

of value (theoretical time of life) to hypothetically improve their health state, or prefer not to trade and keep the same health state. Excellent validity [28] and reliability [29] have been demonstrated for these utilities. They have been utilized in numerous peer-reviewed papers by the authors $[26,27,30-34]$ and other researchers [35-37].

Vision utilities range from 1.00 (bilateral vision $\geq 20 / 20$ permanently) to 0.00 (death). As vision in the better-seeing eye decreases, the associated utility and quality-of-life decrease. The lowest vision anchor utility is 0.26 , which correlates with bilateral no light perception [30]. Our vision results were converted to utilities, then to QALYs (quality-adjusted life-years). People accrue QALYs as they live. The total QALY accrual is calculated by multiplying (utility) $\times$ (years lived at that utility). For example, living at a utility of 0.80 for 3 year accrues 2.40 QALYs $(0.80 \times 3)$, and so forth.

Using the average life expectancy of 9 years [38], we calculated how many QALYs were accrued by the mean triple therapy with $\mathrm{Zx}$ patient versus the mean triple therapy patient. Adverse events included the disutility associated with intravitreal injection, predominantly discomfort up to $24 \mathrm{~h}$. The utility of 0.89 associated with this condition was obtained from 68 patients in the Center for Value-Based Medicine ${ }^{\circledR}$ Time Tradeoff Utility Database, a compendium of over 50,000 patient utilities with acquisition approved by the Wills Eye Hospital Institutional Review Board. There were no cases of endophthalmitis. One vitreous hemorrhage requiring vitrectomy and one retinal detachment occurred, both in the triple therapy cohort. Nonetheless, the incidences of these adverse events were not significant $(\mathrm{p}=0.50$, Fisher Exact Test), and therefore not included in the base case analysis. A 0.002 QALY loss previously associated with PDT adverse event disutilities was used [31].

\section{Cost-utility (cost-effectiveness) analysis}

The model outcome was \$/QALY, or dollars expended per QALY gained from the intervention. This is the costutility (cost-effectiveness) ratio (CUR). Per the Panel on Cost-Effectiveness in Health and Medicine, all QALY accruals and costs were discounted at $3 \%$ annually [39].

\section{Statistics}

Statistics comparing ratios of patients with second eye progression to neovascular AMD were performed with the Chi square test, which was also used to evaluate other categorical variables. Linear variables were compared using the Student's $t$ test. (Microsoft Excel, Bellevue, Washington). Significance was presumed to occur at $\mathrm{p}<0.05$.

The SSM Health Care Institutional Review Board approved this study (approval number 14-07-0540. It adhered to the Helsinki Declaration of 1975, as revised in 1983. All participants signed an informed consent form. A four-year, prospective, randomized, clinical trial comparing triple therapy and triple therapy with $\mathrm{Zx}$ for treating neovascular AMD is currently in its third year. See Clinical Trials.gov (Identifier: NCT 01527435).

\section{Results}

\section{Clinical features}

The mean baseline CNV size in the triple therapy cohort was 7.0 disc areas (DA) (SD $=3.5,95 \%$ CI 6.5-7.5) while that in the triple therapy with $\mathrm{Zx}$ cohort was 7.4 DA $(\mathrm{SD}=3.5,95 \% \mathrm{CI} 6.9-7.9)(\mathrm{p}=0.32)$ (Fig. 1$)$. CNV size ranged from $<1$ DA to 12 DA. In both cohorts with unilateral neovascular AMD, over $90 \%$ of fellow eyes had Age-Related Eye Disease Study, Category 3 AMD [40] with drusen $>125 \mu \mathrm{m}$, typically with pigmentary changes.

The triple therapy cohort, mean visual acuity improved from baseline $20 / 250$ to $20 / 200$ at 12 and 24 months (Table 2), a mean gain of 6 EDTRS letters ( $<<0.0001)$. Visual acuity was stable or improved in $79 \%$ of eyes after 1 year and $87 \%$ after 2 years. The mean number of treatment cycles was 2.1 over 1 year and 2.8 over 2 years. Eyes had a mean reduction in retinal thickness from $265 \mathrm{~m} \mu$ $(\mathrm{SD}=79,95 \% \mathrm{CI} 252-278)$ to $244 \mathrm{~m} \mu(\mathrm{SD}=66,95 \% \mathrm{CI}$ 233-255), $-21 \mathrm{~m} \mu(-8.0 \%)$ microns on OCT, at 2 years $(\mathrm{p}=0.001)$ (Table 3$)$.

Triple therapy plus $\mathrm{Zx}$ eyes had mean vision improve from baseline $20 / 200$ to $20 / 160$ at 12 and 24 months (Table 2), an average gain of 7 EDTRS letters $(\mathrm{p}<0.0001)$. Eighty-three percent of eyes had stable or improved vision at 2 years, $27.5 \%$ gained 15 letters or more on EDTRS, and $17 \%$ were worse by 3 or more lines ( $p=0.85$ versus triple therapy cohort distribution). Overall, the mean number of treatment cycles was 1.6 at 1 year and 2.1 over 2 years. The addition of $\mathrm{Zx}$ reduced the mean 


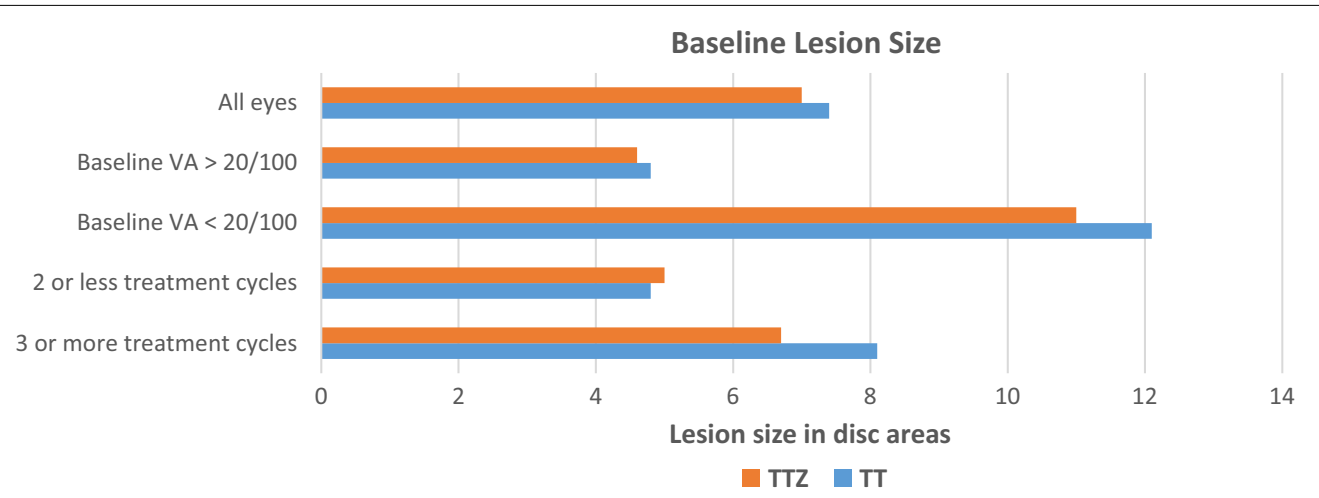

Fig. 1 Baseline lesion size and treatment cycles. Baseline lesion size corresponded significantly to number of treatment cycles required and decreased visual acuity. TTZ triple combination therapy with zeaxanthin, TT triple combination therapy, VA vision. Baseline VA $<20 / 100=20 / 200$ or worse vision ( $p<0.0001$ for baseline VA $>20 / 100$ versus baseline VA $<20 / 100$, as well as for 2 or less treatment cycles versus 3 or more treatment cycles)

Table 3 Central foveal thickness as seen on OCT

\begin{tabular}{llllll}
\hline & $\begin{array}{l}\text { Mean } \\
\text { baseline } \\
\text { CFT }(\boldsymbol{\mu m})\end{array}$ & $\begin{array}{l}\text { Mean } \\
\text { 2-year CFT } \\
(\boldsymbol{\mu m})\end{array}$ & $\begin{array}{l}\text { Mean } \\
\text { change } \\
(\boldsymbol{\mu m})\end{array}$ & $\begin{array}{l}\text { \% Thick- } \\
\text { ness } \\
\text { change } \\
(\%)\end{array}$ & p value \\
\hline $\mathrm{TT}$ & 265 & 244 & -21 & -8.0 & $\mathrm{p}=0.001$ \\
$\mathrm{TTZ}$ & 287 & 232 & -55 & -19.2 & $\mathrm{p}<0.0001$ \\
\hline
\end{tabular}

$T T$ triple combination therapy, TTZ triple combination therapy with zeaxanthin, CFT central foveolar thickness

treatment cycles by $24 \%$ at 1 year and $32 \%$ over 2 years. Eyes had a mean retinal thickness reduction from $287 \mathrm{~m} \mu$ $(\mathrm{SD}=70,95 \% \mathrm{CI} 274-300)$ to $232 \mathrm{~m} \mu(\mathrm{SD}=79,95 \% \mathrm{CI}$ $223-241)$, a decrease of 55 microns $(-19.2 \%)$ on OCT at 24 months $(\mathrm{p}<0.0001)$ (Table 3$)$. In both cohorts, larger baseline lesion size correlated with increased treatment cycles $(\mathrm{p}<0.0001)$ and decreased vision $(\mathrm{p}<0.0001)$. Visual and anatomic results were compared between eyes with classic CNV and occult CNV. No statistical difference between these groups was seen across all parameters analyzed.

The triple therapy cohort had 160 patients with CNV in the first eye and drusen in the fellow eye. Overall, 20 fellow eyes (12.5\%) developed CNV over 2 years, 12 in year one and 8 in year 2 . In the triple therapy plus $\mathrm{Zx}$ cohort, 80 people had CNV in the first eye and drusen in the fellow eye. Overall, 5 fellow eyes $(6.25 \%)$ developed CNV over 2 years, 3 in year 1 and two in year 2 ( $p=0.03$ versus triple therapy cohort) (Fig. 2; Table 4).

\section{Economic analysis}

\section{Patient value gain}

QALYs accrued over 9 years by the triple therapy with Zx, triple therapy and control cohorts are shown in Table 5 . The overall QALY gains for the cohorts are shown in
Table 6. Utilizing the combined-eye model, triple combination therapy with Zx confers an $8.2 \%$ quality-of-life (QOL) gain versus no therapy $(\mathrm{p}<0.0001)$, while triple therapy confers a $6.0 \%$ QOL gain versus no therapy $(p<0.0001)$ The highest QOL gain of $14.1 \%$ occurs in the triple therapy with Zx cohort with the second-eye model.

A comparison of the two treatment cohorts reveals adding Zx enhances QOL by $2.5 \%$ over triple therapy alone $(\mathrm{p}<0.0001)$ (Tables 5, 6). This is the incremental patient value gain. Sixty-six percent of patients in the current study presented with a first-eye model and $34 \%$ a second-eye model when calculating the combined-eye patient value gain. Nonetheless, each treated second-eye patient in the triple therapy with $\mathrm{Zx}$ cohort contributed $2.21 \times$ the value contributed by a treated first-eye patient. The less favorable, first-eye, vision utility data were taken from the Center for Value-Based Medicine Utility Database [23, 24, 26-34].

\section{Costs}

The costs associated with therapeutic strategies are shown in Table 7. The total discounted Zx cost per patient over 9 years was $\$ 2887$. The total triple combination therapy with Zx cost per patient for the combinedeye model was $\$ 10,440$. It dropped to $\$ 8222$ when $Z x$ was given for only 2 years instead of nine. The cost for triple therapy was $\$ 9540$, intermediate between $\mathrm{Zx}$ given for 2 years and 9 years. The base case cost of $\$ 10,440$ in the triple therapy with $\mathrm{Zx}$ cohort was distributed as follows: physician: \$2521 (24\%), diagnostic testing: \$815 (8\%), drugs other than Zx: \$4176 (40 \%), and Zx: \$2887 (28 \%).

\section{Cost-utility (cost-effectiveness)}

The base case, combined-eye, incremental CUR for the use of triple therapy with $\mathrm{Zx}$ referent to 


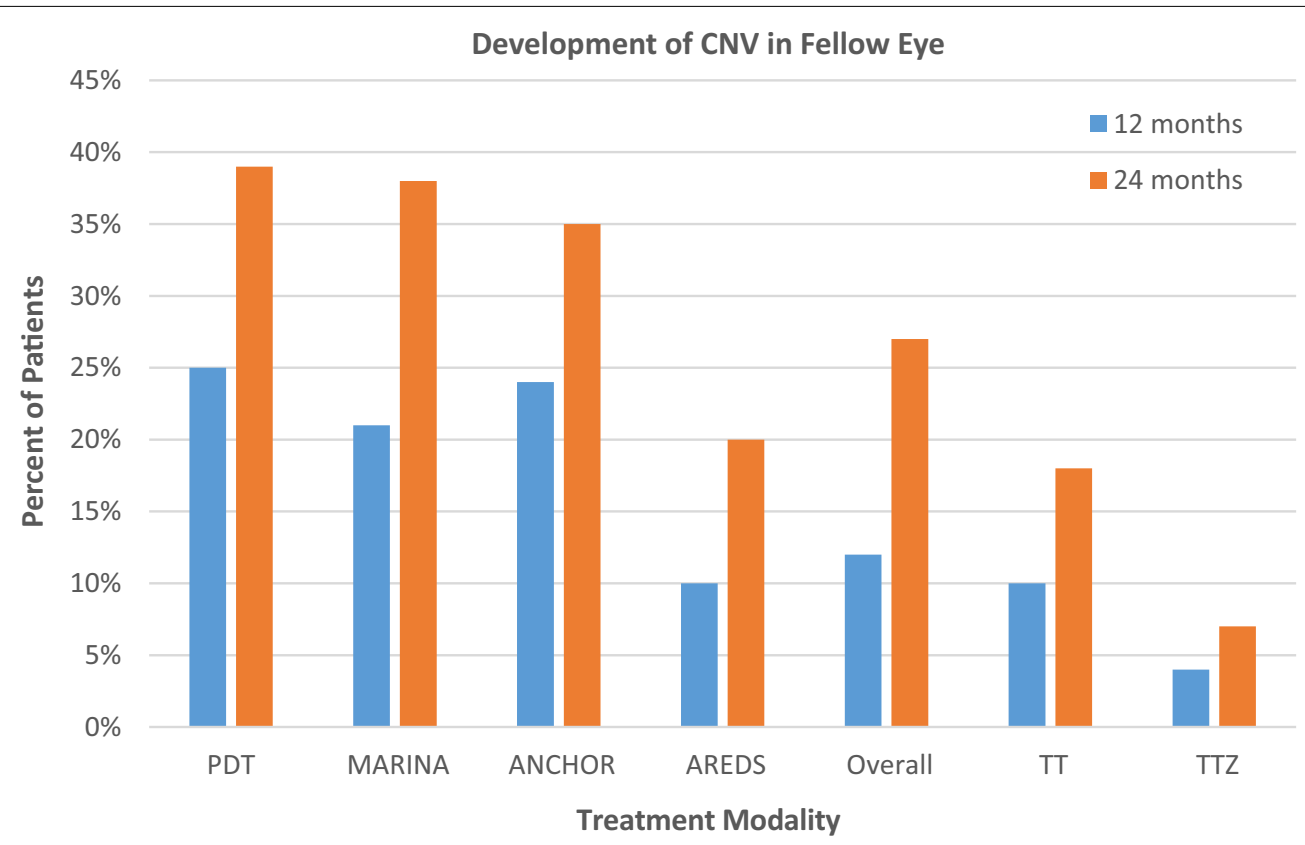

Fig. 2 Choroidal neovascularization conversion in the fellow eye. The percentage of patients that converted to CNV in the fellow eye in the current study and other studies: Barbazetto et al. [41] for ANCHOR, MARINA and PDT photodynamic therapy with verteporfin, Overall numbers from a metaanalysis (Wong et al. Ophthalmology 2008;115:1524), AREDS Age-Related Eye Disease Study [19], TT triple combination therapy in current study, TTZ triple combination therapy with zeaxanthin in current study (CNV choroidal neovascularization). A 24-month comparison of conversion rates to CNV in the fellow eye in the TT and TTZ cohorts showed that zeaxanthin significantly decreased conversion in fellow eyes ( $p=0.03)$. A 24-month MARINA and ANCHOR CNV conversion study in the fellow eye revealed a far greater 24-month rate in MARNA/ANCHOR than in our triple combination therapy cohort $\left(p=0.6 \times 10^{-6}\right)$ or the triple combination therapy cohort with zeaxanthin $\left(p=1.0 \times 10^{-14}\right)$

Table 4 Choroidal neovascularization in the fellow eye developing from 0 to 24 months after baseline versus Barbazetto et al. [41]

\begin{tabular}{llll}
\hline & $\begin{array}{l}\text { Conversions in current study } \\
\text { (conversions/fellow eyes with dry AMD) }\end{array}$ & $\begin{array}{l}\text { Conversions-Barbazetto et al. [41] } \\
\text { (conversions/fellow eyes with dry AMD) }\end{array}$ & p-value \\
\hline TT, 12 months & $12 / 160(20 \%)$ & $100 / 445(22.5 \%)$ & 0.0001 \\
TTZ, 12 months & $3 / 80(3.75 \%)$ & $100 / 445(22.5 \%)$ & 0.00003 \\
TT, 24 months & $20 / 160(12.5 \%)$ & $151 / 445(33.9 \%)$ & 0.0000006 \\
TTZ, 24 months & $5 / 80(6.25 \%)$ & $151 / 445(33.9 \%)$ & $1 \times 1.0^{-14}$ \\
\hline
\end{tabular}

$T T$ triple combination therapy, $T T Z$ triple combination therapy with zeaxanthin, CFT central foveolar thickness

Table 5 QALY (quality-adjusted life-year) accrual associated with the three cohorts over 9 years (discounted at $3 \%$ annually)

\begin{tabular}{llll}
\hline Model & TTZ cohort & TT cohort & $\begin{array}{l}\text { Control } \\
\text { cohort [25] }\end{array}$ \\
\hline First-eye model & 7.202 & 7.050 & 6.749 \\
Second-eye model & 5.269 & 5.016 & 4.616 \\
Combined-eye model & 6.546 & 6.384 & 6.024 \\
\hline
\end{tabular}

$T T Z$ triple therapy with zeaxanthin, $T T$ triple therapy

Combined-eye model $=66 \%$ first-eye model and $34 \%$ second-eye model, Zeaxanthin $=$ Zx

triple therapy alone was \$5302/QALY (Table 8). This assumed Zx was used for 9 years. The average CUR for the use of triple therapy with $Z x$ was $\$ 19,962$ /
QALY, while the average cost-CUR for the use of triple therapy was $\$ 26,574 /$ QALY.

\section{Sensitivity analysis (Table 9)}

Sensitivity analysis assesses the variables of least confidence. In this instance, it demonstrated the incremental CUR for the triple therapy with and without $\mathrm{Zx}$ to range from ( $-\$ 8148 / \mathrm{QALY}$ ) when Zx was used for only the first 2 years to $\$ 23,892 / \mathrm{QALY}$ when $\mathrm{Zx}$ was used for 9 years, but had no benefit after 2 years. The cost of $Z x$ must rise to $\$ 318 /$ month for an incremental CUR of $\$ 100,000 / Q A L Y$. The cost of Zx must rise to $\$ 513 /$ month for a CUR of $\$ 158,000 /$ QALY, or $3 \times$ the US Gross Domestic Product per capita.

Comparing our triple therapy with $\mathrm{Zx}$ cohort data to the higher, fellow eye, $\mathrm{CNV}$ conversion rates noted by 
Table 6 QALY and (percent patient value gains) for triple combination therapy cohorts associated with zeaxanthin use and with no zeaxanthin use

\begin{tabular}{llll}
\hline Model & $\begin{array}{l}\text { TTZ vs. control } \\
\text { cohort }\end{array}$ & $\begin{array}{l}\text { TT vs. control } \\
\text { cohort }\end{array}$ & TTZ vs. TT \\
\hline $\begin{array}{l}\text { First-eye model } \\
\begin{array}{c}\text { Second-eye } \\
\text { model }\end{array}\end{array}$ & $0.453(6.7 \%)$ & $0.339(5.0 \%)$ & $0.115(1.6 \%)$ \\
$\begin{array}{c}\text { Combined-eye } \\
\text { model }\end{array}$ & $0.553(14.1 \%)$ & $0.400(8.7 \%)$ & $0.253(5.0 \%)$ \\
$\begin{array}{c}\text { Combined-eye } \\
\text { model }\end{array}$ & $p<0.0001$ & $0.359(6.0 \%)$ & $0.162(2.5 \%)$ \\
\hline
\end{tabular}

$T T Z$ triple therapy with zeaxanthin, $T T$ triple therapy

Combined-eye model $=66 \%$ first-eye model and $34 \%$ second-eye model,

Zeaxanthin $=$ Zx

Barbazetto et al. [41] there is a 2-year absolute risk reduction of $30.3 \%$ (the $36.6 \%$ incidence of fellow eye CNV in ANCHOR/MARINA minus the $6.3 \%$ incidence of CNV with our triple therapy with $\mathrm{Zx}$ cohort) $\left(\mathrm{p}<1.0 \times 10^{-14}\right)$. The triple therapy cohort also had less $\mathrm{CNV}$ conversions at 2 years $\left(\mathrm{p}=0.6 \times 10^{-6}\right)$. The incremental CUR for $\mathrm{Zx}$ addition drops to ( $-\$ 5601 / \mathrm{QALY})$ with Barbazetto et al. data [41]. The minus CUR indicates that $\mathrm{Zx}$ with triple therapy dominates triple therapy by conferring more patient value for less cost. The average CUR for triple therapy with Zx drops to \$10,052/QALY.

\section{Discussion}

Our case series showed that triple therapy with $\mathrm{Zx}$ yielded a visual result superior to that of triple therapy alone. At the same time, it significantly decreased the onset of $\mathrm{CNV}$ in the fellow eye. That said, both triple therapy with and without $\mathrm{Zx}$ are superior to observation.

The series applied a combination of agents to treat subfoveal CNV in AMD. Anti-VEGF treatment is the mainstay in treatment for neovascular AMD. The MARINA study [11] was associated with monthly injections of ranibizumab. Visual acuity, ophthalmoscopic signs and diagnostic studies all showed significant benefits over 2 years of follow-up in patients with minimally classic or occult lesions. The ANCHOR study [10] found ranibizumab therapy more effective than PDT for predominantly classic, subfoveal CNV. The CATT Study noted that ranibizumab and bevacizumab similarly improved visual acuity [12]. It is difficult to compare patient value gain with those studies since they enrolled patients with a mean vision of $20 / 80$, versus $20 / 200-20 / 250$ in our study. There is a greater potential for value gain when CNV patients are treated earlier in their course with better vision [42].

Ongoing VEGF-inhibitor treatment, however, creates patient and healthcare system burdens. The patient burden may actually cause some to stop treatment before remission [43]. The incidence of serious ocular and systemic adverse events with anti-VEGF injections is low, but rates can increase when therapy is repeatedly applied [44]. In addition, VEGF may play a role in the survival and maintenance of RPE integrity [45].

PDT leads to selective cytotoxicity of vascular endothelial cells by producing oxidative radicals [46]. But despite an early angiographic effect suggesting disappearance of CNV, patients experience a mean visual loss of two ETDRS lines of vision during the first 6 months after treatment $[8,47]$. Studies of the angiogenic effect of PDT

Table 7 Nine-year costs for zeaxanthin and no zeaxanthin triple therapy (2015 US Real dollars, discounted at $3 \%$ annually)

\begin{tabular}{lll}
\hline Model & $\begin{array}{l}\text { No zeaxanthin } \\
\text { treatment } \\
\text { cohort }\end{array}$ & $\begin{array}{l}\text { Triple combination therapy } \\
\text { with zeaxanthin (9 years } \\
\text { of zeaxanthin) }\end{array}$ \\
$\begin{array}{l}\text { First-eye, second-eye or combined-eye } \\
\text { model: the same for all }\end{array}$ & $\$ 9540$ & $\$ 10,440$ \\
\hline
\end{tabular}

Combined-eye model $=66 \%$ 1st-eye model and $34 \%$ 2nd-eye model

$T T Z$ triple combination with zeaxanthin, $T T$ triple combination therapy

Table 8 Cost-utility ratios of triple therapy and triple therapy with zeaxanthin

\begin{tabular}{lll}
\hline Model & $\begin{array}{l}\text { TTZ vs TT } \\
\text { Incremental CUR }\end{array}$ & $\begin{array}{l}\text { TTZ vs. control cohort } \\
\text { Average CUR }\end{array}$ \\
\hline First-eye model & $\$ 7470 / \mathrm{QALY}$ & $\begin{array}{l}\text { TT vs. control cohort } \\
\text { Average CUR }\end{array}$ \\
Second-eye model & $\$ 3395 / \mathrm{QALY}$ & $\$ 22,958 / \mathrm{QALY}$ \\
Combined-eye model & $\$ 5302 / \mathrm{QALY}$ & $\$ 15,926 / \mathrm{QALY}$ \\
\hline
\end{tabular}


Table 9 Sensitivity analysis

\begin{tabular}{|c|c|c|c|}
\hline Model & $\begin{array}{l}\text { Incremental } \\
\text { cost }\end{array}$ & $\begin{array}{l}\text { Incremental } \\
\text { QALY gain }\end{array}$ & \$/QALY \\
\hline \multicolumn{4}{|l|}{ Therapeutic changes in the TTZ cohort } \\
\hline \multicolumn{4}{|l|}{ Base case } \\
\hline Zx daily for 9 years in the triple therapy with Zx cohort & $\$ 859$ & 0.162 & $\$ 5302$ \\
\hline Zx daily for 2 years only in the triple therapy with Zx cohort & $(-\$ 1318)$ & 0.162 & $(-\$ 8148)$ \\
\hline $\begin{array}{l}\text { Two additional treatments: bevacizumab, PDT and dexamethasone, years 3-9 in } \\
\text { both cohorts }\end{array}$ & $\$ 859$ & 0.162 & $\$ 5,312$ \\
\hline Costs in both cohorts are doubled & $\$ 1718$ & 0.162 & $\$ 10,623$ \\
\hline Zx cost over 9 years is doubled from $\$ 30 /$ month to $\$ 60 /$ month & $\$ 3746$ & 0.162 & $\$ 23,154$ \\
\hline Zx cost/month for cost-utility ratio of $\$ 50,000 / Q A L Y$ & $\$ 150$ & 0.162 & $0 \$ 50,000$ \\
\hline Zx cost/month for cost-utility ratio of $\$ 100,000 / Q A L Y$ & $\$ 318$ & 0.162 & $\$ 100,000$ \\
\hline $\begin{array}{l}\text { Zx cost/month for cost-utility ratio of } \$ 158,000 / Q A L Y(\text { WHO upper limit for cost-effective- } \\
\text { ness }=3 \times \text { GDP per capita) }\end{array}$ & $\$ 513$ & 0.162 & $\$ 158,000$ \\
\hline \multicolumn{4}{|l|}{ Altering patient value gains associated with TTZ } \\
\hline Doubling patient value gains in both cohorts & $\$ 859$ & 0.324 & $\$ 2,656$ \\
\hline Halving the patient value gain from $Z x$ & $\$ 859$ & 0.081 & $\$ 10,623$ \\
\hline Loss of Zx benefit after year 2 with 2 years of Zx therapy in the TTZ cohort & $(-\$ 1318)$ & 0.036 & $(-\$ 36,665)$ \\
\hline Loss of Zx benefit after year 2, with 9 years of Zx therapy in the TTZ cohort & $\$ 859$ & 0.036 & $\$ 23,892$ \\
\hline Zx incremental QALY gain for $\$ 50,000 / Q A L Y$ & $\$ 859$ & 0.017 & $\$ 50,000$ \\
\hline Zx incremental QALY gain for $\$ 100,000 / Q A L Y$ & $\$ 859$ & 0.0086 & $\$ 100,000$ \\
\hline $\begin{array}{l}\text { Zx incremental QALY gain required for } \$ 158,000 / \text { QALY (WHO upper limit for cost-effective- } \\
\text { ness }=3 \times 2015 \text { US GDP per capita) }\end{array}$ & $\$ 859$ & 0.0054 & $\$ 158,000$ \\
\hline \multicolumn{4}{|c|}{ Integrating the therapeutic QALY gain and costs saved by TTZ decreasing the onset of neovascular AMD in the fellow eye: combined-eye model } \\
\hline $\begin{array}{l}\text { Zx daily for } 9 \text { years in the TTZ cohort vs. TT cohort-assumes that TTZ yields an absolute risk } \\
\text { reduction of CNV in the } 2 \text { nd eye of } 30.3 \%\end{array}$ & $(-\$ 2291)$ & 0.362 & $(-\$ 6332)$ \\
\hline \multicolumn{4}{|l|}{ Average cost-utility } \\
\hline $\begin{array}{l}\text { Zx daily for } 9 \text { years in the TTZ cohort vs. TT cohort: assumes TTZ reduces the absolute risk } \\
\text { reduction of CNV in the } 2 \text { nd eye by } 30.3 \%\end{array}$ & 7249 & 0.7212 & $\$ 10,052$ \\
\hline
\end{tabular}

A negative cost-utility ratio indicates that neovascular age-related macular degeneration triple therapy with zeaxanthin provides greater patient value than triple therapy without zeaxanthin and is also less expensive than triple therapy without zeaxanthin.) (Dollars are 2015 US real dollars discounted at $3 \%$ annually. QALYs are discounted at $3 \%$ annually.

Incremental cost-utility of TTZ vs. TT cohorts, combined-eye model

QALY quality-adjusted life-year, $\$ / Q A L Y$ dollars expended per QALY gained, $P D T$ photodynamic therapy with verteporfin, GDP gross domestic product, $T T Z$ triple combination therapy with zeaxanthin, $T T$ triple combination therapy, Zx zeaxanthin, WHO World Health Organization

show increased VEGF, VEGF-R and PEDF in eyes [9]. This suggests combination therapy with an anti-VEGF agent is reasonable.

Corticosteroids stabilize the blood retinal barrier and down regulation of inflammation [48]. In addition, they have anti-fibrotic and anti-angiogenic activity, the latter which can last for 3 months [48].

Multiple studies have suggested combination therapy addresses the mechanisms of disease progression. Combination PDT and ranibizumab therapy in AMD patients with $\mathrm{CNV}$ has been associated with $\mathrm{CNV}$ occlusion, reduced retinal edema and improved vision [49]. Wan and colleagues [50] treated 174 eyes with PDT, then intravitreal bevacizumab 30 days later. Over a mean 10 months, patients received an average of 3.0 bevacizumab injections and 1.4 PDT treatments. After stabilization, the mean treatment-free interval was 193 days, and $52 \%$ of patients required no post-induction retreatment. Visual acuity improved at 2, 4, and 6 months.

In a number of population-based studies, lutein and Zx levels have been inversely associated with the risk of AMD. The POLA study [51] found high total plasma lutein and Zx reduced the risk of AMD by $79 \%$, with a particularly strong association between $\mathrm{Zx}$ and AMD. Subjects with high levels of plasma Zx had a $93 \%$ reduced risk of AMD vs. those with low levels. Similar studies in China [52] and the UK [6], also showed Zx had a greater positive influence. In the UK study, a $50 \%$ reduced risk of AMD was noted in people with high plasma $Z x$. 
The reasons for Zx benefit are elusive. Evidence suggests a role for $\mathrm{Zx}$ as a filter to blue light, preventing it from entering the outer retina [53]. Short wavelength blue light contains energy, and filtering this light may limit metabolic insult. Zeaxanthin also serves as an antioxidant; it consumes singlet oxygen and may quench free radicals generated by normal retinal metabolism. Increased levels of $\mathrm{Zx}$ also inhibit VEGF levels [53, 54].

We recognize the limitations of consecutive case series versus a randomized controlled trial. However, our information suggests triple therapy with bevacizumab, dexamethasone and PDT is a viable option for wet AMD, and that oral Zx enhances that benefit. The percentage of stable or improved eyes in both of our cohorts (more than $80 \%$ ) is very encouraging. Oral Zx may also provide a protective benefit for the fellow eye. This requires further study, but suggests protection against CNV development could considerably preserve vision.

While some clinicians believe monthly injections of anti-VEGF drugs are not necessary with monotherapy, studies still show less visual acuity gains with less frequent dosing [12, 55]. Subjects receiving triple therapy plus Zx, however, kept the same vision from 12 to 24 months.

\section{Economic analysis \\ Cost-effectiveness}

The use of oral $\mathrm{Zx}$ with triple combination therapy is very cost-effective, with an incremental cost-utility ratio (CUR) of \$5302/QALY. No formal US formal cost-effectiveness criteria exist, but a CUR $\angle \$ 100,000 /$ QALY is often thought cost-effective [24]. World Health Organization [56] criteria state a CUR $<1 x$ Gross Domestic Product (GDP) per capita ( US $\$ 53,000$ [57]) is very cost-effective, while a CUR $<3 \times$ GDP per capita ( US $\$ 158,000)$ is cost-effective. The National Institute for Health and Care Excellence (NICE) in the UK suggests a CUR $<£ 20,000 /$ QALY ( US $\$ 29,750)$ is cost-effective, although $€ 30,000 /$ QALY ( US \$44,326) is sometimes allowed [58]. By any of the above criteria, triple combination therapy for neovascular AMD appears to be very cost-effective. The addition of oral Zx is more cost-effective yet. GDP per capita data suggest adding Zx to triple therapy would be cost-effective in 127 of the world's 198 countries, even if healthcare costs were similar to the US [57].

\section{Conclusions}

In summary, neovascular AMD triple therapy is comparatively effective and cost-effective. It requires considerably less treatment than needed with monotherapy. Adding oral $\mathrm{Zx}$ appears to further reduce the treatment cycles required, and possibly reduce fellow eye CNV development. Nonetheless, the results of a randomized trial will be critically important.

\section{Abbreviations}

AMD: age-related macular degeneration; NVAMD: neovascular age-related macular degeneration; AREDS: Age Related Eye Diseases Study; QALY: qualityadjusted life-year; \$QALY: dollars expended per quality-adjusted life-year gained; VBM: value-based medicine; CUR: cost-utility ratio; Zx: zeaxanthin; TT: triple combination therapy; TTZ: triple combination therapy with zeaxanthin; GDP: gross domestic product; CNV: choroidal neovascularization; VEGF: vascular endothelial growth factor; ETDRS: Early Treatment Diabetic Retinopathy Study.

\section{Authors' contributions}

RJO, EP and DLG participated in the conceptualization of the study and the design of the study. RJO and EP enrolled and examined the participants. RJO, GCB and MMB performed the analyses. RJO, EP, DLG, GCB and MMB wrote the manuscript. All authors read and approved the final manuscript.

\section{Author details}

${ }^{1}$ The Center for Value-Based Medicine ${ }^{\circledR}$, Box 335, Flourtown, PA 19031, USA ${ }^{2}$ The Retina Center of St. Louis County, St. Louis, MO, USA. ${ }^{3}$ ZeaVision, 680F Crown Industrial Court, Chesterfield, MO 63005, USA. ${ }^{4}$ Retina Service, Wills Eye Hospital, Jefferson Medical College, philadelphia, PA, USA. ${ }^{5}$ Research Department, Wills Eye Hospital, Jefferson Medical College, philadelphia, PA, USA.

\section{Acknowledgements}

None.

\section{Competing interests}

The study was supported in part by a grant from ZeaVision, Inc., Chesterfield, MO. DL Gierhart has intellectual property rights around zeaxanthin. RJ Olk has phantom shares in ZeaVision. Drs. G. Brown and M. Brown are shareholders in the Center for Value-Based Medicine ${ }^{\circledR}$.

Received: 12 August 2015 Accepted: 27 August 2015

Published online: 09 November 2015

\section{References}

1. Bressler NM. Age-related macular degeneration is the leading cause of blindness. JAMA. 2004;291:1900-1.

2. Resnikoff S, Pascolini D, Etya'ale D, Kocur I, Pararajasegram R, Pokharel GP, Marioti SP. Global data on visual impairment in the year 2002. Bull World Health Organ. 2004;82:844-51.

3. Lopez PF, Sippy BD, Lambert HM, Thac AB, Hinton DR. Transdifferentiated retinal pigment epithelial cells are immunoreactive for vascular endothelial growth factor in surgically excised age-related macular degeneration-related choroidal neovascular membranes. Invest Ophthalmol Vis Sci. 1996;27:85-868.

4. Frank RN, Amin RH, Eliott D, Puklin JE, Abrams GW. Basic fibroblast growth factor and vascular endothelial growth factor are present in epiretinal and choroidal neovascular membranes. Am J Ophthalmol. 1996:122:393-403.

5. Kliffen M, Sharma HS, Mooy CM, Kerkvliet S, de Jong PT. Increased expression of angiogenic growth factors in age-related maculopathy. $\mathrm{Br} J$ Ophthalmol. 1997;81:154-62.

6. Gale CR, Hall NF, Phillips DI, Martyn CN. Lutein and zeaxanthin status and risk of age-related macular degeneration. Invest Ophthalmol Vis Sci. 2003:44:2461-5

7. Obana A, Hiramitsu T, Gohto Y, Ohira A, Mizuno S, Hirano T, Bernstein PS, Fujii H, Iseki K, Tantio M, Hotta Y. Macular carotenoid levels of normal subjects and age-related maculopathy patients in a Japanese population. Ophthalmology. 2008;115:147-57.

8. Treatment of Age-Related Macular Degeneration with Photodynamic Therapy (TAP) Study Group. Photodynamic therapy of subfoveal choroidal neovascularization in age-related macular degeneration with verteporfin: two-year results of 2 randomized clinical trials-TAP Report 2. Arch Ophthalmol. 2001;119:198-207. 
9. Schmidt-Erfurth U, Schlötzer-Schrehard U, Cursiefen C, Michels S, Beckendorf A, Naumann GO. Influence of photodynamic therapy on expression of vascular endothelial growth factor (VEGF), VEGF Receptor 3 , and pigment epithelium-derived factor. Invest Ophthalmol Vis Sci. 2003;44:4473-80.

10. Brown DM, Michels M, Kaiser PK, Heier JS, lanchuley T, ANCHOR Study Group. Ranibizumab versus verteporfin photodynamic therapy for neovascular age-related macular degeneration: 2-year results of the ANCHOR study. Ophthalmology. 2009;116:57.e5-57.

11. Rosenfeld PJ, Brown DM, Heier JS, Boyer DS, Kaiser PK, Chung CY, Kim RY, MARINA Study Group. Ranibizumab for neovascular age-related macular degeneration. N Engl J Med. 2006;355:1419-31.

12. CATT Research Group, Martin DF, Maguire MG, Ying GS, Grunwald JE, Fine SL, Jaffe GJ. Ranibizumab and bevacizumab for neovascular age-related macular degeneration. N Engl J Med. 2011;364:1897-908 (Epub 2011

\section{Apr 28).}

13. Lalwani GA, Rosenfeld PJ, Fung AE, Dubovy SR, Michels S, Feuer W, David $J$, Flynn HW Jr, Ewquiabro M. A variable-dosing regimen with intravitreal ranibizumab for neovascular age-related macular degeneration: year 2 of the PrONTO Study. Am J Ophthalmol. 2009;148:43-58.

14. Perez VL, Caspi RR. Immune mechanisms in inflammatory and degenerative eye disease. Trends Immunol. 2015;36:354-63.

15. Spaide RF. Rationale for combination therapies for choroidal neovascularization. Am J Ophthalmol. 2006;141:149-56.

16. Augustin AJ, Puls S, Offermann I. Triple therapy for choroidal neovascularization due to age-related macular degeneration: verteporfin PDT, bevacizumab, and dexamethasone. Retina. 2007;27:133-40.

17. Seddon JM, Ajani UA, Sperduto RD, Hiller R, Blair N, Burton TC, Farber MD Gragoudas ES, Haller J, Miller DT, et al. Dietary carotenoids, vitamins A, $C$, and $E$, and advanced age-related macular degeneration. Eye Disease Case-Control Study Group. JAMA. 1994;272:1413-20.

18. Ho L, van Leeuwen R, Witteman J, van Duijn CM, Uitterlinden AG, Hofman A, de Jong PT, Vingerling JR, Klaver CC. Reducing the genetic risk of agerelated macular degeneration with dietary antioxidants, zinc, and $\omega-3$ fatty acids: the rotterdam study. Arch Ophthalmol. 2011;129:758-66.

19. Age-Related Eye Disease Study Research Group, SanGiovanni JP, Chew EY, Clemons TE, Ferris FL 3rd, Gensler G, Lindblad AS, Milton RC, Seddon JM, Sperduto RD. The relationship of dietary carotenoid and vitamin A, E, and $C$ intake with age-related macular degeneration in a case-control study: AREDS Report No. 22. Arch Ophthalmol. 2007;125:1225-32.

20. Tan JS, Wang JJ, Flood V, Rochtchina E, Smooth W, Mitchell P. Dietary Antioxidants and the long-term incidence of age-related macular degeneration: the Blue Mountains Eye Study. Ophthalmology. 2008;115:334-41.

21. Shin JY, Woo SJ, Yu HG, Park KH. Comparison of efficacy and safety between half-fluence and full-fluence photodynamic therapy for chronic central serous chorioretinopathy. Retina. 2011;31:119-26.

22. Kovacs KD, Quirk MT, Kinoshita T, Gautam S, Ceron OM, Murtha TJ, Arroyo JG. A retrospective analysis of triple combination therapy with intravitreal bevacizumab, posterior sub-tenon's triamcinolone acetonide, and lowfluence verteporfin photodynamic therapy in patients with neovascular age-related macular degeneration. Retina. 2011;31:446-52.

23. Brown MM, Brown GC, Sharma S, Landy J. Health care economic analyses and value-based medicine. Surv Ophthalmol. 2003;48:204-23.

24. Brown MM, Brown GC, Sharma S. Evidence-Based to Value-Based Medicine. Chicago: AMA Press; 2005. p. 1-324.

25. Shah AR, DelPriore LV. Progressive visual loss in subfoveal exudation in age-related macular degeneration: a meta-analysis using LineweaverBurke plots. Am J Ophthalmol. 2007;143:83-9.

26. Brown GC, Brown MM, Brown H, Peet JS. A value-based medicine analysis of ranibizumab (MARINA Study) for the treatment of subfoveal neovascular macular degeneration. Ophthalmology. 2008;115:1039-45.

27. Brown GC, Brown MM, Menezes A, Busbee BG, Lieske HB, Lieske PA. Cataract surgery cost-utility revisited in 2012. A new economic paradigm. Ophthalmology. 2013;120:2367-76.

28. Sharma S, Brown GC, Brown MM, Hollands H, Robbins R, Shah G. Validity of the time trade-off and standard gamble methods of utility assessment in retinal patients. Br J Ophthalmol. 2002;86:493-6.

29. Brown GC, Brown MM, Sharma S, Beauchamp G, Hollands H. The reproducibility of ophthalmic utility values. Trans Am Ophthalmol Soc. 2001:99:199-203.
30. Brown GC. Vision and quality of life. Trans Am Ophthalmol Soc. 1999;97:473-512.

31. Brown GC, Brown MM, Brown HC, Kindermann S, Sharma S. A ValueBased Medicine comparison of interventions for subfoveal neovascular macular degeneration. Ophthalmology. 2007;114(1170-8):4.

32. Brown MM, Brown GC, Sharma S, Kistler J, Brown H. Utility values associated with blindness in an adult population. Br J Ophthalmol. 2001;85:327-31.

33. Brown MM, Brown GC, Sharma S, Landy J. Quality of life with visual acuity loss from diabetic retinopathy and age-related macular degeneration. Arch Ophthalmol. 2002;120:481-4

34. Brown GC, Brown MM, Lieske HB, Lieske PA, Brown KS. Comparative effectiveness and cost-effectiveness analyses on the implantable miniature telescope. Ophthalmology. 2011;118:1834-43.

35. Finger RP, Fenwick E, Hirneiss CW, Hsueh A, Guymer RH, Lamoureux EL, Keeffe JE. Visual impairment as a function of visual acuity in both eyes and its impact on patient reported preferences. PLoS One. 2013;8(12):e81042.

36. Chang JS, Smiddy WE. Cost evaluation of surgical and pharmaceutical options in treatment in treatment for vitreomacular adhesions and macular holes. Ophthalmology. 2014;121:1720-6.

37. Frampton G, Harris P, Cooper K, Lotery A, Shepherd J. The clinical effectiveness and cost-effectiveness of second-eye cataract surgery: a systematic review and economic evaluation. Health Technol Assess 2014;18:1-205.

38. Arias E. United States life tables, 2010. Nat Vital Stat Reports. 2014;63:9-10.

39. Siegel JE, Weinstein MC, Russell LB, Gold MR. Panel on Cost-Effectiveness in Health and Medicine: recommendations for reporting cost-effectiveness analyses. JAMA. 1996;276:1339-41.

40. The Eye Diseases Prevalence Research Group. Prevalence of agerelated macular degeneration in the United States. Arch Ophthalmol. 2004;122:564-72

41. Barbazetto IA, Saroj N, Shapiro H, Wong P, Ho AC, Freund KB. Incidence of new choroidal neovascularization in fellow eyes of patients treated in the MARINA and ANCHOR trials. Am J Ophthalmol. 2010;149:939-46.

42. Boyer DS, Antoszyk AN, Awh CC, Bhisitkul RB, Shapiro H, Acharya NR, MARINA Study Group. Subgroup analysis of the MARINA study of ranibizumab in neovascular age-related macular degeneration. Ophthalmology. 2007;114:246-52.

43. Oishi A, Mandai M, Nishida A, Hata M, Matsuki T, Kurimoto Y. Remission and dropout rate of anti-VEGF therapy for age-related macular degeneration. Eur J Ophthalmol. 2011;21:777-82.

44. Van der Reis MI, La Heij EC, De Jong-Hesse Y, Ringens PJ, Hendrikse F, Schouten JS. A systematic review of the adverse events of intravitreal anti-vascular endothelial growth factor injections. Retina. 2011;31:1449-69.

45. Ford KM, Saint-Geniez M, Walshe T, Zahr A, D'Amore PA. Expression and role of VEGF in the adult retinal pigment epithelium. IOVS. 2011;52:9478-87.

46. Schmidt-Erfurth U, Hasan T. Mechanisms of action of photodynamic therapy with verteporfin for the treatment of age-related macular degeneration. Surv Ophthalmol. 2000;45:195-214.

47. Treatment of Age-Related Macular Degeneration with Photodynamic Therapy (TAP) Study Group. Photodynamic therapy of subfoveal choroidal neovascularization in age-related macular degeneration with verteporfin: one-year results 2 randomized clinical trials-TAP Report 1. Arch Ophthalmol. 1999;117:1329-45.

48. Becerra EM, Morescalchi F, Gandolfo F, Danzi P, Nascimbeni G, Arcidiacono $B$, Semeraro F. Clinical evidence of intravitreal triamcinolone acetonide in the management of age-related macular degeneration. Curr Drug Targets. 2011;12:149-72.

49. Kiss CG, Simader C, Michels S, Schmidt-Erfurth U. Combination of verteporfin photodynamic therapy and ranibizumab: effects on retinal anatomy, choroidal perfusion and visual function in the protect study. $\mathrm{Br}$ J Ophthalmol. 2008;92:1620-7.

50. Wan MJ, Hooper PL, Sheidow TG. Combination therapy in exudative age-related macular degeneration: visual outcomes following combined treatment with photodynamic therapy and intravitreal bevacizumab. Can J Ophthalmol. 2010;45:375-80. 
51. Delcourt C, Carriere I, Delange M, Barberger-Gateau P, Schalch W, the POLA Study Group. Plasma Lutein and Zeaxanthin and other carotenoids as modifiable risk factors for age-related maculopathy and cataract: the POLA study. Invest Ophthalmol Vis Sci. 2006;47:2329-35.

52. Zhou H, Zhao X, Johnson E, Lim A, Sun E, Yu J, Zhang Y, Liu X, Snellingen T, Shang F, Liu N. Serum carotenoids and risk of age-related macular degeneration in a Chinese population. Invest Ophthalmol Vis Sci. 2011;52:4338-44.

53. Loane E, Kelliher C, Beatty S, Nolan JM. The rationale and evidence base for a protective role of macular pigment in age-related maculopathy. $\mathrm{Br} J$ Ophthalmol. 2008;92:1163-8.

54. Fernández-Roberdo P, Recalde S, Arnáiz G, Salinas-Alamán A, Sádaba LM, Moreno-Orduña M, Garcia-Layana A. Effect of zeaxanthin and antioxidant supplementation on vascular endothelial growth factor (VEGF) expression in apolipoprotein-E deficient mice. Curr Eye Res. 2009;34:543-52.
55. Fung $A E$, Lalwani GA, Rosenfeld PJ, Dubovy SR, Michels S, Feuer WJ, Puliafito CA, David JL, Flynn HW Jr, Esquiabro M. An optical coherence tomography-guided, variable dosing regimen with intravitreal ranibizumab (Lucentis) for neovascular age-related macular degeneration. Am J Ophthalmol. 2007;143:566-83.

56. The World Health Organization. The World Health Report 2002_Reducing Risks, Promoting Healthy Life, pp 47-96. From the Internet http:// www.who.int/whr/2002/en/index.html. Accessed March 182015.

57. Central Intelligence Agency. Country GDP per capita. World Factbook. From the Internet https://www.cia.gov/library/publications/the-worldfactbook/rankorder/rawdata_2004.txt. Accessed March 20, 2015.

58. National Institute for Health and Care Excellence. The social care guidance manual. From the Internet http://www.nice.org.uk/article/pmg10/ resources/non-guidance-the-social-care-guidance-manual-pdf. Accessed March 27, 15

\section{Submit your next manuscript to BioMed Central and take full advantage of:}

- Convenient online submission

- Thorough peer review

- No space constraints or color figure charges

- Immediate publication on acceptance

- Inclusion in PubMed, CAS, Scopus and Google Scholar

- Research which is freely available for redistribution

Submit your manuscript at

www.biomedcentral.com/submit

C Biomed Central 